Bangladesh J. Bot. 49(4): 913-918, 2020 (December)

\title{
PHYTOCHEMICAL ASSESSMENT OF IPHIONA AUCHERI (BIOSS.) ANDERB. AND ITS CYTOTOXIC, ANTIOXIDANT AND ANTIDIABETIC ACTIVITIES
}

\author{
Muhammad Abdur Rehman Shah, Rahmat Ali Khan*and Mushtaq Ahmed \\ Department of Biotechnology, University of Science and Technology Bannu (28100), \\ KPK, Pakistan
}

Keywords: $\alpha$-amylase, Brine shrimp, Methanolic extract, Phytochemicals assessment

\begin{abstract}
The presence of phytochemical constituents and estimation of total phenolic contents in Iphiona aucheri (Bioss.) Anderb. stem and assessment of their cytotoxic, total antioxidant and anti-diabetic activity were investigated. All fractions were assessed for phytochemicals, cytotoxic activity, total phenolic contents, antioxidant and anti-diabetic characteristics. Saponins, glycosides, protein and amino acids, carbohydrates and flavonoids were found in aqueous fraction and methanolic extract while they were absent in $n$-hexane fraction except glycosides and protein. The crude methanolic extract $(70.3 \pm 1.9 \%)$ revealed highest brine shrimp mortalities. Except $n$-hexane fraction others indicated considerable antioxidant activities via DPPH, $\mathrm{ABTS}^{*+}$ and $\mathrm{H}_{2} \mathrm{O}_{2}$ assays. Crude methanolic extract expressed higher inhibition of $\alpha$-amylase $(60.71 \pm 0.89 \%)$ than glucophage $(54.92 \pm 0.56 \%)$. Non significant correlation of total phenolic contents with percentage antioxidant and anti-diabetic activities of crude methanolic extract and its various fractions was observed in all cases.
\end{abstract}

\section{Introduction}

Plants having medicinal properties have been used long ago for the treatment of various diseases. Virtually the presence of thousands of bioactive constituents, generally known as phytochemicals in these plants are responsible for their therapeutic characteristics (Afanas'ev 2010). The phytochemicals may be present in fruit, seeds, flowers, leaves, stems, roots and bark (Gurib-Fakim 2006).

Iphiona aucheri belonging to Asteraceae is scattered in Pakistan, Oman, North-East Africa, the Arabian Peninsula and Iran (Anderberg 1985). In Pakistan, it is distributed in Khuzdar, Chaghi, Mekran, Lasbela, and Loralai districts (Kakar et al. 2012). Previously, antibacterial activities of Iphiona aucheri against $S$. aureus, E. coli, S. pyogenes and K. ponumoniae were reported (Kakar et al. 2012). The minerals, namely $\mathrm{Na}, \mathrm{K}, \mathrm{Ca}, \mathrm{Fe}$ and $\mathrm{Ni}$ were reported in Iphiona aucheri while $\mathrm{Al}$ was found absent (Lanjwani et al. 2016).

The aim of this study was is to carry out the phytochemical assessment and estimation of total phenolic contents, cytotoxic, antioxidant and antidiabetic properties of methanolic extract and its $n$-hexane, chloroform and aqueous fractions of Iphiona aucheri stem by using different standard assays. This investigation will provide the base for isolation and purification of natural therapeutic compounds for the treatment of cancer, diabetics and oxidative stress-related diseases in the future.

\section{Materials and Methods}

Stems of Iphiona aucheri (Bioss.) Anderb. (AR-123) were collected in March, 2017 from district, Bannu, Pakistan. Its taxonomic study was carried out by Prof. Abdur Rehman, Govt. Postgraduate College Bannu, Khyber Pakhtoon Khawa (KPK) Pakistan.

*Author for correspondence: <Rahmatgul_81@yahoo.com>. 
The collected stems were washed with tap water, dried under shade and pulverized into fine powder by using pestle and mortar. A $500 \mathrm{~g}$ powder was extracted in $70 \%$ methanol (1.5 liter), evaporated at room temperature and finally was stored $14.37 \mathrm{~g}$ of extract in falcon tube for further use. The said extract $(10 \mathrm{~g})$ was sequentially extracted at room temperature with $n$-hexane, chloroform and aqueous ( $300 \mathrm{ml}$ each) using separating funnel to elude any kind of damages to the filtrate. The resultant extract of each solvent; $n$-hexane $(1.3 \mathrm{~g})$, chloroform $(2.19 \mathrm{~g})$ and water $(4.98 \mathrm{~g})$ was stored for further use.

Standard methods viz., foam test, ferric chlorides, alkaline reagent test, Millon's test and Fehling test were employed to conduct phytochemicals screening of methanolic extract of Iphiona aucheri stems and its different fractions to investigate the presence of saponins, flavonoids, protein and amino acids, glycosides and carbohydrates.

Brine shrimp lethality bioassay was opted to find out the cytotoxic activity of methanolic extract of Iphiona aucheri stems and its different fractions with the help of Meyer protocols (Meyer et al. 1982).

Total phenolic contents contained in the plant extract and its various fractions was determined by using Folin-Ciocalteu reagents following the method of Singleton and Rossi (1965).

Antioxidant assays indirectly measure the ability of compounds to interrupt free radicals by scavenging or trapping. Methanolic crude extract of Iphiona aucheri stem and its various fractions were subjected to DPPH, ABTS and $\mathrm{H}_{2} \mathrm{O}_{2}$ free radicals scavenging assays to analyze their antioxidant activities by engaging the free radicals. DPPH (1, 1-diphenyl-2-picrylhydrazyl) radical scavenging assay is a very refined method for estimation of in vitro antioxidant activity.

The DPPH, ABTS and $\mathrm{H}_{2} \mathrm{O}_{2}$ free scavenging by plant extract were determined according to protocol of Gyamfi et al. (1999), Re et al. (1999), Wettasinghe and Shahidi (2000).

The potential of the samples to scavenge the free radicals was calculated by using the following equation:

$\%$ inhibition $=\left(\mathrm{A}_{1}-\mathrm{A}_{2} / \mathrm{A}_{1}\right) \times 100$

where, $\mathrm{A}_{1}=$ The absorbance of the control and $\mathrm{A}_{2}=$ The absorbance of the samples.

The $\alpha$-amylase inhibitory activities of methanolic extract and its different fractions were determined through Worthington Enzyme Manual (Kwon et al. 2007) protocol.

Amylase inhibition $(\%)=$ Control absorbance (blank) - Sample absorbance/control absorbance $\times 100$.

Statistical analysis was carried out through GraphPad Prism software.

\section{Results and Discussion}

Phytochemical screening of Iphiona aucheri stem crude methanolic extract and its various fractions revealed the presence of saponins, glycosides, protein, amino acids, carbohydrates and flavonoids in aqueous fraction and methanolic extract while they were absent in $n$-hexane fraction except glycosides and protein. Glycosides, protein and amino acids and flavonoids were also found in chloroform fraction while saponins and carbohydrates were not found. The results are presented in Table 1. Further study of the desired plant extract depends on the phytochemicals present in the plant extract. In the recent era cancer is an emerging group of life treating diseases. The side effects of synthetic commercially available medicines have boosted the search of phytochemicals having cytotoxic/anti-cancer properties. In this experiment, the highest cytotoxic properties expressed by crude methanolic extract $(70.3 \pm 1.9 \%)$ while lowest by $n$-hexane fraction $(30.8 \pm 1.2 \%)$ at a concentration of $1000 \mu \mathrm{g} / \mathrm{ml}$ in brine shrimp lethality bioassay. The percentage mortalities of shrimp larvae of different applied samples are shown in Table 2. Similar results 
were observed during cytotoxic activities of Hapllophyllum tuberculatum (Al-Muniri and Hossain 2017) and Coccinia grandis L. (Laboni et al. 2017). This investigation uncovered the fact that the Iphiona aucheri stem extract possesses phytochemical components having cytotoxic properties.

The $n$-hexane $(9.18 \pm 1.92 \mathrm{mg} \mathrm{GAE} / \mathrm{g})$, an aqueous fraction $(9.81 \pm 1.69)$ and crude methanolic extract $(16.09 \pm 1.52)$ had lesser phenolic contents when compared with chloroform fraction $(21.30 \pm 2.04 \mathrm{mg} \mathrm{GAE} / \mathrm{g})$. The results are comparable with earlier reports of total phenolic contents of plant extracts of Salvia officinalis (7.78 \pm 0.0041$)$, Teucrium polium (8.29 \pm 0.0064), Ocimum basilicum (13.1 \pm 0.021), Mentha pulegium (16.34 \pm 0.011$)$, Agaricus campestris (18.96 \pm 0.0079$)$, Thymus algeriensis $(18.73 \pm 4.59)$, Mentha spicata $(19.65 \pm 0.001)$, Hedysarum scoparium (26.71 \pm 0.15 ) (Roukia et al. (2013), Soumia et al. (2014). The results ensure that Iphiona aucheri stem is a potent source of phenolic compounds.

Table 1. Phytochemical screening of methanolic extract, chloroform and aqueous fractions of Iphiona aucheri stems.

\begin{tabular}{|c|c|c|c|c|c|c|}
\hline \multirow{2}{*}{$\begin{array}{l}\text { Sl. } \\
\text { no. }\end{array}$} & \multicolumn{2}{|l|}{ Phytochemicals and tests } & \multicolumn{4}{|c|}{ Crude methanolic exract and its fractions } \\
\hline & Phytochemical & Tests & $\begin{array}{l}\text { Aqueous } \\
\text { fraction }\end{array}$ & $\begin{array}{l}\text { Methanolic } \\
\text { fraction }\end{array}$ & $\begin{array}{l}\text { Chloroform } \\
\text { fraction }\end{array}$ & $\begin{array}{l}n \text {-hexane } \\
\text { fraction }\end{array}$ \\
\hline 1 & Saponins & Foam test & + & + & - & - \\
\hline 2 & Flavonoids & Alkaline reagent test & + & + & + & - \\
\hline 3 & Glycosides & Fehling & + & + & + & + \\
\hline 4 & Carbohydrates & Milisch's test & + & + & - & - \\
\hline 5 & Protein and amino acids & Biuret test & + & + & + & + \\
\hline
\end{tabular}

Table 2. Percentage lethality of brine shrimps caused by crude methanolic extract and its various fractions of Iphiona aucheri stems.

\begin{tabular}{llllll}
\hline \multirow{2}{*}{$\begin{array}{l}\text { Conc. } \\
(\mu \mathrm{g} / \mathrm{ml})\end{array}$} & \multicolumn{3}{c}{ Crude methanolic extract and its fractions $(\%)$ lethality } & \\
\cline { 2 - 5 } & $\begin{array}{l}\text { Methanolic } \\
\text { extract }\end{array}$ & $\begin{array}{l}\text { Chloroform } \\
\text { fraction }\end{array}$ & $\begin{array}{l}\text { Aqueous } \\
\text { fraction }\end{array}$ & $\begin{array}{l}n \text {-Hexane } \\
\text { fraction }\end{array}$ & Control \\
\hline 100 & $30.5 \pm 1.7$ & $20.2 \pm 1.3$ & $30.6 \pm 1.7$ & $10.6 \pm 1.9$ & 00 \\
250 & $40.2 \pm 1.3$ & $40.4 \pm 1.6$ & $40.4 \pm 1.1$ & $10.3 \pm 1.6$ & 00 \\
500 & $60.7 \pm 1.4$ & $50.1 \pm 1.5$ & $50.9 \pm 1.3$ & $20.7 \pm 1.8$ & $10.3 \pm 1.1$ \\
1000 & $70.3 \pm 1.9$ & $50.5 \pm 1.1$ & $60.7 \pm 1.6$ & $30.8 \pm 1.2$ & 00 \\
\hline
\end{tabular}

Table 3. Phenolic content (mg/g gallic acid equivalent) of crude methanolic extract and its various fractions of Iphiona aucheri stems.

\begin{tabular}{lcccc}
\hline Extracts & Methanolic extract & Chloroform fraction & Aqueous fraction & $n$-Hexane fraction \\
\hline Total phenolic contents & $16.09 \pm 1.52$ & $21.30 \pm 2.04$ & $9.81 \pm 1.69$ & $9.18 \pm 1.92$ \\
\hline
\end{tabular}

The highest antioxidant activity $(76.68 \%)$ was revealed by crude methanolic extract followed by an aqueous fraction (62.93\%) while $n$-hexane expressed lowest antioxidant activity (23.55\%) at the concentrations of $2 \mathrm{mg} / \mathrm{ml}$. Antioxidant activity of ascorbic acid recorded was $80.43 \%$ at the same concentration. Fig. 1 indicates antioxidant properties of the mentioned standard and extracts 
samples. The results showed that the antioxidant activities of the Iphiona aucheri stem methanolic extract and its different fractions are concentration dependent. Similar results were observed in previous studies of Leucas aspera (Willd) link (Annapandian and Rajagopal 2017) and Pogostemon species (Kaliyappan et al. 2017).

In ABTS radical cation assay, it was observed that the methanolic extract exhibited maximum antioxidant activity $(80.52 \%)$ followed by $n$-hexane $(54.65 \%)$, aqueous $(47.43 \%)$ and chloroform fractions (45.11\%, Fig. 2)

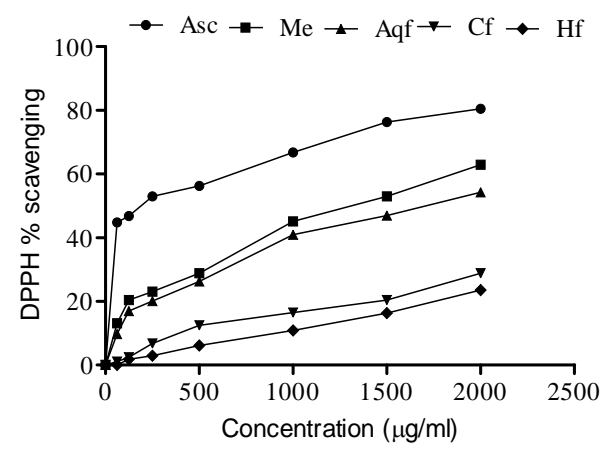

Fig. 1. DPPH free radical scavenging capability of Iphiona aucheri stem's methanolic extract and its fractions. Cf : Chloroform fraction, Me : Methanolic extract, Aqf: Aqueous fraction, Hf : $n$-Hexane fraction and Asc: Ascorbic acid

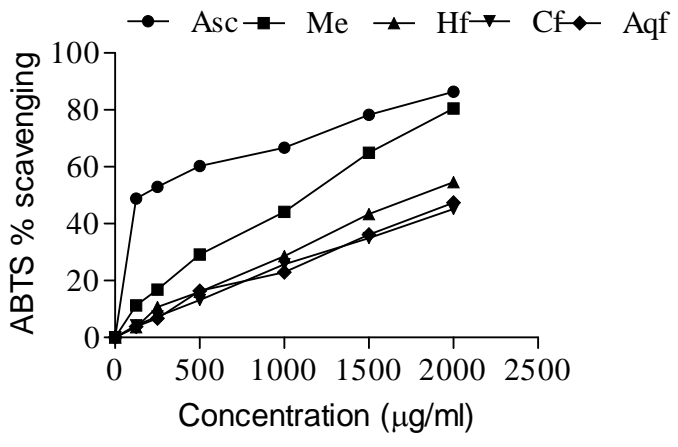

Fig. 2. ABTS free radical scavenging capability of Iphiona aucheri stem's methanolic extract and its fractions. $\mathrm{Cf}$ : Chloroform fraction, Me : Methanolic extract, Aqf : Aqueous fraction, Hf : $n$-Hexane fraction and Asc : Ascorbic acid.

Hydrogen peroxide $\left(\mathrm{H}_{2} \mathrm{O}_{2}\right)$ is transformed into more toxic hydroxyl radical in the presence of transition metal and can cause cellular damages. The generation of singlet oxygen by reacting with hypochlorous acid $(\mathrm{HOCl})$ or with superoxide anion or chloramines in living systems makes it more reactive and deteriorative (Karadag et al. 2009). Methanol extract and its water, chloroform and $n$-hexane fractions expressed 32.85, 31.55, 28.06 and $19.16 \%$ scavenging activity, respectively on hydrogen peroxide at the concentration of $2000 \mu \mathrm{g} / \mathrm{ml}$ whereas ascorbic acid showed $61.04 \%$ scavenging activity at the same concentration (Fig. 3). Previous studies have also uncovered the connection between the scavenging characteristic of plant extracts and phytochemicals, such as flavonoids and total phenolics (Tiwari et al. 2014).

The assessment of anti-diabetic activities of crude methanolic extract and its various fractions of Iphiona aucheri stems was carried out by $\alpha$-amylase enzyme inhibition assay. Results are presented in Fig. 4. The said property of glucophage (commercially available medicine, used as a standard) methanolic extract and aqueous fraction were recorded 54.92, 60.71 and 32.70\%, respectively. Its chloroform and $n$-hexane fractions did not show anti-diabetic activities. The recent research project suggests that the Iphiona aucheri stem contain substantial cytotoxic, antioxidant and anti-diabetic properties. The methanolic crude extract has moderate phenolic contents when compared with its fractions but expressed maximum antioxidant activities (DPPH, ABTS and $\mathrm{H}_{2} \mathrm{O}_{2}$ ) and antidiabetic activities ( $\alpha$-amylase inhibition) while the chloroform fraction with highest phenolic contents exhibited lowest antioxidant and anti-diabetic activities. Moreover, among all antioxidants methods (DPPH, ABTS and $\mathrm{H}_{2} \mathrm{O}_{2}$ ) the methanolic extract has the highest antioxidant activities followed by its water and chloroform fractions. In case of Iphiona aucheri stem extracts indirect correlation of phenolic contents with antioxidant and antidiabetic activities was observed. The higher anti-diabetic activities of methanolic extract than Glucophage (merck®) 
ensure that the applied extract has a significant amount of active naturally occurring anti-diabetic component.

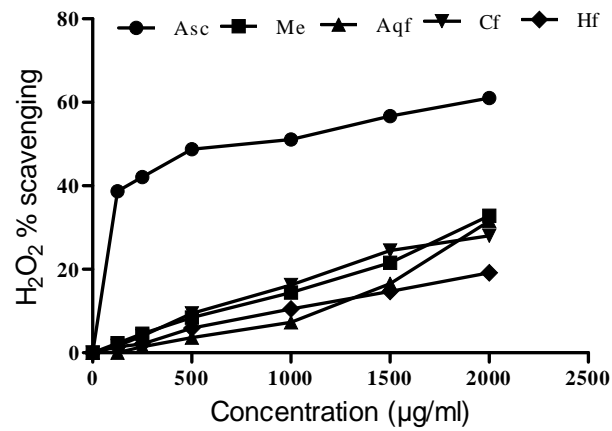

Fig. 3. $\mathrm{H}_{2} \mathrm{O}_{2}$ free radical scavenging capability of Iphiona aucheri stem's methanolic extract and its fractions. Cf : Chloroform fraction, Me : Methanolic extract, Aqf : Aqueous fraction, Hf: $n$-Hexane fraction and Asc : Ascorbic acid.

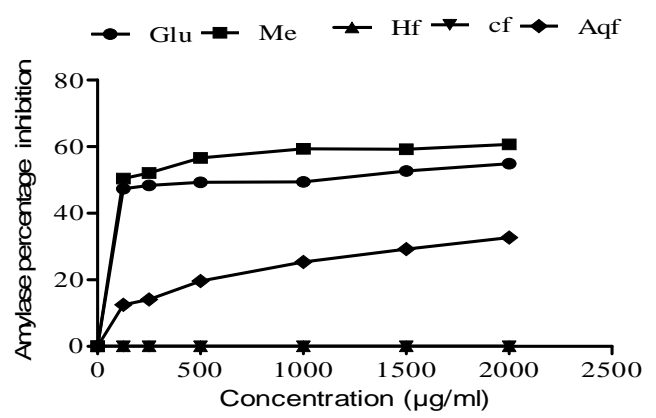

Fig. 4. Anti-diabetic activity of Iphiona aucheri stem's methanolic extract and its fractions, Cf : Chloroform fraction, Hf : n-Hexane fraction, Me : Methanolic extract and Glu: glucophage *(Cf: Chloroform fraction and $\mathrm{Hf}: n$-Hexane fraction did not show anti-diabetic activities).

Table 4. Iphiona aucheri stems methanol extract and its different soluble fractions were used in the correlation, $p$ value (two tailed) and ns: Nonsignificant.

\begin{tabular}{llcc}
\hline Sl. no. & Assays & Correlation $\mathrm{R}^{2}$ phenolics & Significance \\
\hline 1 & $\%$ DPPH radical scavenging ability & 0.3129 & $\mathrm{~ns}$ \\
2 & $\mathrm{ABTS}^{\bullet+} \%$ scavenging ability & 0.1857 & $\mathrm{~ns}$ \\
3 & $\% \mathrm{H}_{2} \mathrm{O}_{2}$ scavenging & 0.0962 & $\mathrm{~ns}$ \\
4 & $\%$ amylase inhibition & 0.5810 & $\mathrm{~ns}$ \\
\hline
\end{tabular}

Non-significant correlation of total phenolic contents with percentage antioxidant and antidiabetic activities of crude methanolic extract and its various fractions was observed in all cases (Pearson correlation). Analogous results were reported in previous studies (Sahreen et al. 2017). DPPH, ABTS and $\mathrm{H}_{2} \mathrm{O}_{2}$ assays revealed that chloroform fraction containing maximum phenolic content $(21.30 \pm 2.04 \mathrm{mg} \mathrm{GAE} / \mathrm{g})$ expressed minimum antioxidant and anti-diabetic properties. The said correlations are indicated in Table 4.

Finally, it may be concluded that the Iphiona aucheri stem extract is a potent source of antioxidant, cytotoxic and anti-diabetic compounds. Its further analysis will depict its pharmacological properties.

\section{Acknowledgments}

The experiments were performed in the Biotechnology Laboratory, University of Science and Technology Bannu, KPK, Pakistan.

\section{References}

Afanas'ev I 2010. Signaling and damaging functions of free radicals in aging-free radical theory, hormesis, and TOR. Aging Dis. 1: 75-88. 
Al-Muniri RMS and Hossain MA 2017. Evaluation of antioxidant and cytotoxic activities of different extracts of folk medicinal plant Hapllophyllum tuberculatum. Egypt J. Basic Appl. Sci. 4: 101-106

Anderberg A 1985. The genus Iphiona (Compositae-Inuleae). Nord. J. Bot. 5: 169-194.

Annapandian VM and Rajagopal SS 2017. Phytochemical Evaluation and In vitro Antioxidant Activity of various solvent extracts of Leucas aspera (Willd.) Link leaves. Free Radic. Antioxid. 7: 166-171.

Gurib-Fakim A 2006. Medicinal plants: Traditions of yesterday and drugs of tomorrow. Mol. Aspects Med. 27: $1-93$

Gyamfi MA, Yonamine M and Aniya Y 1999. Free-radical scavenging action of medicinal herbs from Ghana: Thonningia sanguinea on experimentally-induced liver injuries. Vasc. Pharmacol. 32: 661-667.

Kakar SA, Tareen RB, Kakar MA, Jabeen H, Kakar S-u-R, Al-Kahraman Y and Shafee M 2012. Screening of antibacterial activity of four medicinal plants of Balochistan-Pakistan. Pak. J. Bot. 44: 245-250.

Kaliyappan M, Nallasamy N, Thirumuruthy K and Priya S 2017. In vitro anti-oxidant activity in methanolic extracts of five Pogostemon species. Free Radic. Antioxid. 7: 190-194.

Karadag A, Ozcelik B and Saner S 2009. Review of methods to determine antioxidant capacities. Food Anal. Method. 2: 41-60.

Kwon YI, Apostolidis E and Shetty K 2007. Evaluation of pepper (Capsicum annuum) for management of diabetes and hypertension. J. Food Biochem. 31: 370-385.

Laboni FR, Sultana T, Kamal S, Karim S, Das S, Harun-Or-Rashid M and Shahriar M 2017. Biological investigations of the ethanol extract of the aerial part (leaf) of Coccinia grandis L. J. Pharmacogn Phytochem. 6: 134-138

Lanjwani AH, Ghanghro AB, Memon FM, Memon MN, Ghanghro IH and Channa MJ 2016. Extraction of trace minerals from some important medicinal plants growing in district of Kamber/Shahdadkot, Sind. Pak. Rawal Med. J. 41: 360-362.

Meyer B, Ferrigni N, Putnam J, Jacobsen L, Nichols DJ and McLaughlin JL 1982. Brine shrimp: A convenient general bioassay for active plant constituents. Planta Med. 45: 31-34.

Re R, Pellegrini N, Proteggente A, Pannala A, Yang M and Rice-Evans C 1999. Antioxidant activity applying an improved ABTS radical cation decolorization assay. Free Radic. Biol. Med. 26: 1231-1237

Roukia H, Mahfoud HM, Farah R and Didi OM 2013. Antimicrobial activity of phenolic extract from Teucrium polium geyrii (Lamiaceae). Plant Phcog. Commn. 3: 35.

Sahreen S, Khan MR and Khan RA 2017. Evaluation of antioxidant profile of various solvent extracts of Carissa opaca leaves: an edible plant. Chem. Cent. J. 11: 83.

Singleton V and Rossi JA 1965. Colorimetry of total phenolics with phosphomolybdic-phosphotungstic acid reagents. Am. J. Enol. Vitic. 16: 144-158.

Soumia K, Tahar D, Lynda L, Saida B, Chabane C and Hafidha M 2014. Antioxidant and antimicrobial activities of selected medicinal plants. J. Coast Life Med. 2: 478-483.

Tiwari AK, Kumar DA, Sweeya PS, Chauhan HA, Lavanya V, Sireesha K and Zehra A 2014. Vegetables' juice influences polyol pathway by multiple mechanisms in favour of reducing development of oxidative stress and resultant diabetic complications. Pharmacogn. Mag. 10: S383-S391.

Wettasinghe M and Shahidi F 2000. Scavenging of reactive-oxygen species and DPPH free radicals by extracts of borage and evening primrose meals. Food Chem.70: 17-26.

(Manuscript received on 25 March, 2019; revised on 12 October, 2019) 